Total number of pages: 36

Total number of tables: 0

Total number of figures: 14

\title{
The apparent mass and mechanical impedance of the hand and the transmission of vibration to the fingers, hand, and arm
}

Enrico Concettonia and Michael J. Griffin ${ }^{\mathrm{b}}$

${ }^{a}$ Research Group of Mechanical and Thermal Measurements, Department of Mechanics, Polytechnic University of Marche, Ancona, Via Brecce Bianche, 60131, IT

${ }^{\mathrm{b}}$ Human Factors Research Unit, Institute of Sound and Vibration Research, University of Southampton, Southampton SO17 1BJ, UK

Correspondence address:

Professor Michael J. Griffin

Human Factors Research Unit,

Institute of Sound and Vibration Research,

University of Southampton, Southampton SO17 1BJ, UK

M.J.Griffin@soton.ac.uk 


\begin{abstract}
Although hand-transmitted vibration causes injury and disease, most often evident in the fingers, the biodynamic responses of the fingers, hand, and arm are not yet well understood. A method of investigating the motion of the entire finger-hand-arm system, based on the simultaneous measurement of the biodynamic response at the driving point and the transmissibility to many points on the finger-hand-arm system, is illustrated. Fourteen male subjects participated in an experiment in which they pushed down on a vertically vibrating metal plate with their right forearm pronated and their elbow bent at $90^{\circ}$. The apparent mass and mechanical impedance of the finger-hand-arm system were measured for each of seven different contact conditions between the plate and the fingers and hand. Simultaneously, the vibration of the fingers, hand, and arm was measured at 41 locations using a scanning laser Doppler vibrometer. Transmissibilities showed how the vibration was transmitted along the arm and allowed the construction of spectral operating deflection shapes showing the vibration pattern of the fingers, hand, and arm for each of the seven contact conditions. The vibration patterns at critical frequencies for each contact condition have been used to explain features in the driving point biodynamic responses and the vibration behaviour of the hand-arm system. Spectral operating deflection shapes for the upper limb assist the interpretation of driving point biodynamic responses and help to advance understanding required to predict, explain, and control the various effects of hand-transmitted vibration.
\end{abstract}




\section{Introduction}

Predictions of the risk of developing the hand-arm vibration syndrome are currently based on International Standard ISO 5349 [1] that specifies methods for measuring, evaluating, and reporting exposures to hand-transmitted vibration. Daily exposures to handtransmitted vibration are expressed in terms of the frequency-weighted acceleration, where the characteristics of the frequency-weighting filter (i.e., $W_{\mathrm{h}}$ ) are specified in ISO 8041 [2]. Epidemiological studies have not shown high agreement in all occupational groups between the observed risk of developing vibration-induced white finger and the risk predicted by the ISO 5349 model - both overestimation and underestimation of the risks have been reported (Lidström [3]; Bovenzi et al. [4]; Reynolds et al. [5], [6]; Griffin [7], [8]; Bovenzi [9]; Griffin et al. [10]). It has been argued that the current ISO frequency-weighting may be inappropriate for the assessment of vibration-induced vascular effects because it does not take into account the biodynamic coupling between tool and the operator (e.g., Burström [11]).

The biodynamic response of the entire hand-arm system has been investigated in several studies (e.g., Burström [12]; Gurram et al. [13], [14]; Dong et al. [15], [16]; Aldien et al. [17]). In International Standard ISO 10068 [18] the response of the hand-arm system is represented by the driving point free mechanical impedance (i.e., the complex ratio in the frequency domain between the force and velocity measured at the excitation point). The vibration energy absorption (or power absorption) by the whole hand has also been investigated, partly because some studies have suggested it is correlated with vibration injuries, including vibration-induced white finger (e.g., Burström and Lundström [19]; Sörensson and Burström [20]; Burström and Lundström [21]). However, the symptoms of vibration-induced white finger are localized in the fingers (Bovenzi [9]), so there is a need to also understand the biodynamic responses of the fingers. This cannot be inferred from the driving point mechanical impedance of the whole hand-arm system as defined in ISO 10068 [18]: the relatively small mass of the fingers means their contribution to the impedance of the entire hand and arm is negligible. The responses of the fingers have been studied using instrumented handles that allow the measurement of the force and the acceleration at the fingers and the palm of the hand. In this way it has been possible to calculate the combined biodynamic response of the two halves of the hand (i.e., the palm of the hand and the fingers) involved in a 'clamp like' grip of a handle (Dong et al. [15], [16], [22], [23], [24], [25]).

A high resolution map of the point impedance at different points on the hand-arm system has not been constructed because it requires simultaneous measurement of the 
acceleration and force at each point of contact between a handle and the hand. If the handle is rigid over the frequency range of the excitation, the acceleration is the same at all points, but the local contact force cannot be estimated because it depends on the spatial distribution of the pressure exerted by the hand on the handle.

The transmissibility between a vibration 'input' and the acceleration on the body will reflect the local response at the 'output' (e.g., on the fingers, hand, or arm). Transmissibility has been investigated along the spines of people subjected to whole-body vibration (e.g., Matsumoto and Griffin [26]; Kitazaki and Griffin [27]) and there have been equivalent studies of transmissibility along the hand-arm system. Sörensson and Burström [20] measured transmissibility from the palm of the hand to the knuckle, the wrist, and the elbow so as to calculate the flow of energy in the $x_{\mathrm{h}}$ direction using a laser-Doppler vibrometer. Valentino et al. [28] used a laser Doppler vibrometer to measure the velocity of the tissues of the hand and tried to correlate this velocity with haemodynamic effects on operators working with hydraulic hammers. Scalise et al. [29] used a similar laser Doppler vibrometer to measure the transmissibility in the $\mathrm{z}_{\mathrm{h}}$ direction to six points (on the proximal and distal phalanges of the index, ring and little fingers) of the gripping hand and studied how the transmission of vibration depended on the grip and push forces applied by subjects. These studies demonstrated that laser Doppler vibrometry is a suitable means for measuring the transmissibility of the hand and arm. Compared to accelerometers, laser Doppler vibrometry is relatively non-intrusive and avoids loading problems arising from the application of accelerometers to the skin (Kitazaki and Griffin [30]; Pinotti et al. [31]).

A laser Doppler vibrometer can be equipped with a scanning system: usually two moving mirrors that deflect the laser beam to different points on a vibrating surface so that vibration can be quickly measured at several locations. Rossi and Tomasini [32] [33] proposed the use of a laser Doppler vibrometer equipped with a scanning system to measure the vibration velocity at numerous points on the surface of the hand in different postures and Deboli et al. [34] used the same system to build a map of the velocity distribution over the back of the hand gripping the handle of a pedestrian-controlled twowheeled tractor.

The study reported in this paper was designed to measure simultaneously the driving point biodynamic response of the entire hand-arm system (in terms of apparent mass and mechanical impedance) and the transmissibility to many points on the surface of the handarm system. This allowed the visualization of the vibration pattern on the finger-hand-arm system through the calculation of spectral operating deflection shapes. It was expected that the biodynamic response of the finger-hand-arm system would be influenced by the relative motion between its component parts, and that the visualisation of the spectral 
operating deflection shapes would make it possible to interpret the apparent mass and mechanical impedance measured at the driving point in terms of the motions of the fingers, hand, and arm.

\section{Materials and Methods}

\subsection{Experimental conditions}

The inter-phalangeal joints and the metacarpal-phalangeal joints defined seven coupling conditions between a rigid flat plate and the hand (Figure 1). Conditions \#1 to \#4 were designed to study the transmissibility from the finger to the elbow and conditions \#5 to \#7 allowed the measurement of the transmissibility from the palm of the hand to the fingertips.

\section{FIGURE 1 ABOUT HERE}

The locations on the surfaces of the fingers, hands, and arm at which vibration was measured, and to which transmissibility was determined, were selected as being clearly identifiable and able to provide information on the vibration of the structure of the hand. On the knuckles, on the back of the hand, and on most parts of the arm, the points were selected where bones are not covered by a thick layer of soft tissue, and it was assumed that the vibration measured on the skin could represent the vibration of the whole handarm system. A total of 41 locations were defined (Figure 2):

- 14 points on the knuckles and inter-phalangeal joints: two on the thumb and three on other four fingers;

- 10 points on the rear of the hand: along the arcs of two concentric circles, with five in each arc;

- 17 points on the arm: one at the elbow joint and 16 in two parallel rows of eight points each along the forearm.

\section{FIGURE 2 ABOUT HERE}

A scanning grid was marked on the skin of each subject with white children's face paint to assist directing the laser to the points, to improve the light scattered back from the skin (Tomasini et al. [35]), and to avoid collecting light scattered by the tissues beneath the skin, which can increase noise in the Doppler signal.

To minimise the duration of the experiment and the vibration exposure of subjects, the 17 points on the arm were not measured in conditions \#5, \#6 and \#7. 
The vibration was measured for 10 seconds at each point in succession. With 5 seconds pause after each measurement, a set of measurements took 11 minutes for conditions \#1, \#2, \#3, and \#4, and 6 minutes for conditions \#5, \#6, and \#7.

The different hand-plate coupling conditions had the same average contact pressure. A push force of $25 \mathrm{~N}$ was employed when pushing with the whole hand (i.e., condition \#1) and the force reduced proportionately as the contact area reduced, based on the hand prints of each subject.

\subsection{Subjects}

Fourteen healthy male subjects from the University of Southampton, aged between 21 and 52 years, with mean (and standard deviation) height, weight and body mass index of 1.76 (0.08) $\mathrm{m}, 69.6(7.4) \mathrm{kg}, 22.37(1.53) \mathrm{kg} / \mathrm{m}^{2}$, respectively, participated in the experiment.

The seven test conditions were presented to the 14 subjects in a partially counterbalanced design such that the order of presenting the conditions was fully balanced over the subject group.

The experiment was approved by the Human Experimentation, Safety and Ethics Committee of the Institute of Sound and Vibration Research at the University of Southampton.

\subsection{Vibration generation and measurement}

The experimental instrumentation and inter-connections between the equipment are illustrated in Figure 3.

\section{FIGURE 3 ABOUT HERE}

Vertical vibration of the hand was provided by a $20 \times 15 \mathrm{~cm}$ aluminium plate mounted on an electrodynamic vibrator (Derritron, VP30). Two load cells (Burster $\mathrm{GmbH}$ ) connected in parallel and placed beneath the plate were used to measure force at the driving point. An accelerometer (Endevco 233E) was fastened to the middle of the plate to monitor the input acceleration. The stimulus was an approximately flat constant-bandwidth acceleration power spectrum in the range 5 to $500 \mathrm{~Hz}$ at $17 \mathrm{~ms}^{-2}$ r.m.s. (unweighted).

Subjects sat adjacent to the vibrator and placed their right hands on the aluminium plate. The height and position of the seat were adjusted so that the elbow was at $90^{\circ}$ with the subject pushing down on the plate with the arm pronated. According to ISO 8727 [36], the vertical vibration was along the $x_{\mathrm{h}}$-axis of the hand-arm basicentric coordinate system (Figure 3). 
A computer screen in front of the subjects provided visual feedback of their downward force on the plate, and this was measured continuously during the experiment.

A commercial scanning laser Doppler vibrometer (Polytec GmbH, PSV400) was used to measure the velocity at 41 points from the fingertips to the elbow.

Force and acceleration at the driving point and the velocity at each point on the grid were acquired at a sampling rate of 5120 samples per second using a National Instruments $\mathrm{PCl} / \mathrm{MCl} 12-$ bit data acquisition board. Analogue $1000-\mathrm{Hz}$ low-pass filters were used to avoid aliasing. The software for signal generation, data acquisition and analysis, subject visual feedback, and triggering the movement of the laser to the different points on the grid was developed using National Instruments LabVIEW (version 7.1.1).

Before commencing the experiment, transfer functions between the accelerometer and several points on the unloaded plate were measured in order to compare the accelerometer and vibrometer signals and to verify that the structure providing the stimulus was rigid in the frequency range of interest (i.e., up to $500 \mathrm{~Hz}$ ).

\subsection{Analysis methods}

The transmissibility, the driving point apparent mass, and the driving point mechanical impedance were calculated using the cross-spectral density method:

$$
\operatorname{Tr}_{i}(f)=\frac{S_{A, i}(f)}{S_{A, A}(f)} \quad A M(f)=\frac{S_{F, A}(f)}{S_{A, A}(f)} \quad M I(f)=\frac{S_{F, V}(f)}{S_{V, V}(f)}
$$

where $\operatorname{Tr}_{i}(f)$ is the transmissibility function between the driving point and the $\mathrm{i}^{\text {th }}$ point on the arm, $S_{A, I}(f)$ is the cross power spectrum of the acceleration at the driving point and at the $\mathrm{i}^{\text {th }}$ point, $S_{A, A}(f)$ is the acceleration power spectrum at the driving point, $A M(f)$ is the driving point apparent mass, $S_{F, A}(f)$ is the cross power spectrum of the driving point force and acceleration, $M I(f)$ is the driving point mechanical impedance, $S_{F, V}(f)$ is the cross power spectrum of the driving point force and velocity, $S_{V, V}(f)$ is the velocity power spectrum at the driving point.

The acceleration on the arm was calculated by differentiation of the velocity measured by the laser vibrometer. The velocity at the driving point was calculated by integration of the acceleration measured by the accelerometer. All the cross-spectral densities and the power spectral densities were calculated using a DFT window length of 2560 samples and Hanning window with no overlap and a spectral frequency resolution of $2 \mathrm{~Hz}$.

Before calculating the apparent mass and the mechanical impedance, mass cancellation was carried out in the frequency domain. 
From the magnitude and phase of the set of 41 transmissibilities it was possible to calculate the spectral operating deflection shapes of the hand-arm structure. This analysis allows the determination of the vibration pattern of a system at each frequency under specific 'operating conditions'. The vibration response pattern can then be shown in different ways, in this study as an animated geometric model for the measuring points on the structure.

\section{Results and Discussion}

\subsection{Apparent mass and mechanical impedance}

The means of the moduli of the driving point apparent mass and the driving point mechanical impedance over all 14 subjects and all conditions are presented in Figure 4. To assist comparison with other measurements, both the apparent mass and the mechanical impedance are discussed below.

\section{FIGURE 4 ABOUT HERE}

\section{Apparent mass}

Conditions \#1, \#5 and \#6 show a similar behaviour, with only one resonance peak between 32 and $36 \mathrm{~Hz}$ with an apparent mass of $0.642 \mathrm{~kg}, 0.737 \mathrm{~kg}$, and $0.732 \mathrm{~kg}$, respectively. This indicates that vibration of the fingertip does not greatly influence the biodynamic response measured at the driving point: the fingers have a small mass compared to the rest of the hand-arm system. The apparent mass is comparable to that previously measured for 12 subjects pushing their palms down on a 25-mm diameter plate (O’Boyle and Griffin [37]).

In condition \#2, all subjects showed a first resonance between 10 and $16 \mathrm{~Hz}$, with a mean apparent mass of $0.44 \mathrm{~kg}$. The mean apparent mass then decreases to $0.125 \mathrm{~kg}$ in the range 26 to $46 \mathrm{~Hz}$ and then rises to a second peak around $70 \mathrm{~Hz}$, where the mean apparent mass is $0.16 \mathrm{~kg}$. However, the frequency of this resonance varied between subjects from about 52 to $90 \mathrm{~Hz}$. There are no other known studies of the apparent mass of the hand with the coupling used in condition \#2.

The response measured in condition \#3 is similar to that in condition \#2 but attenuated by about $50 \%$. There is a visible peak around $12 \mathrm{~Hz}$ with an apparent mass of $0.247 \mathrm{~kg}$, but the second peak at a higher frequency has almost disappeared. The apparent mass of every subject showed a second small peak, but at a frequency that varied over a wide range (between 30 and $90 \mathrm{~Hz}$ ), so that the averaging caused it to disappear from the mean apparent mass. 
In condition \#4, no resonances are visible and the response is attenuated by about $50 \%$ compared to condition \#3.

Condition \#7 shows, at low frequencies, a behaviour similar to condition \#1, with a resonance peak of $0.665 \mathrm{~kg}$ between 16 and $28 \mathrm{~Hz}$. Another resonance with an apparent mass of $0.235 \mathrm{~kg}$ is visible in the range $58-70 \mathrm{~Hz}$, probably due to vibration of the fingers.

\section{Mechanical impedance}

As with the apparent mass, the mechanical impedance in conditions \#1, \#5 and \#6 is similar. There is a resonance in the range $40-50 \mathrm{~Hz}$ at values of $165 \mathrm{~N} . \mathrm{s} / \mathrm{m}, 174 \mathrm{~N} . \mathrm{s} / \mathrm{m}$, and $167 \mathrm{~N} . \mathrm{s} / \mathrm{m}$, respectively. The impedance decreases as the frequency increases from about 50 to $130 \mathrm{~Hz}$, but increases as the frequency increases from 130 to $400 \mathrm{~Hz}$.

Previous measurements of the driving point mechanical impedance of the human hand grasping a vibrating handle show similarities to each other, although with some unexplained differences (Gurram et al. [13]). The impedance when pushing down on a flat plate in condition \#1 of the present study is broadly similar to that obtained with the hand grasping a handle in the studies reviewed by Gurram et al. [13] (Figure 5). The impedance measured in the present study is mostly greater at low frequencies but less at higher frequencies than others have measured. The studies reported by Gurram et al. [13] used sine sweep or stepped sine stimuli that have been reported to give lower impedance than random excitation at low frequencies and greater impedance at higher frequencies (Gurram et al. [14]). Precise mass cancellation is required to obtain accurate mechanical impedance at high frequencies - the impedance of the hand is small at frequencies greater than $200 \mathrm{~Hz}$.

\section{FIGURE 5 ABOUT HERE}

Condition \#2 exhibits a strange behaviour, with three resonance peaks of 38,84 , and 86 N.s/m at about $14 \mathrm{~Hz}, 100 \mathrm{~Hz}$ and $150 \mathrm{~Hz}$, respectively. No study with similar conditions has been found in the literature but the findings are similar to the distribution of mechanical impedance along the $\mathrm{z}_{\mathrm{h}}$-axis at the fingers and the palm calculated for a hand gripping a handle (Dong et al. [23]). At the fingers, both functions have a similar frequency-dependence in the modulus and phase, although in the present study the peaks are at a lower frequency and the impedance is mainly lower.

As in the apparent mass, the impedance in condition \#3 is similar to that in condition \#2, but attenuated by about $45 \%$. There is still a small peak of $20 \mathrm{~N} . \mathrm{s} / \mathrm{m}$ at $12 \mathrm{~Hz}$, and a second broad peak of $55 \mathrm{~N} . \mathrm{s} / \mathrm{m}$ around $160 \mathrm{~Hz}$. In condition \#4 no resonance is visible and, compared to condition \#3, the response is attenuated by about $30 \%$. 
Condition \#7 shows a response similar to conditions \#1, \#5 and \#6 at frequencies less than about $34 \mathrm{~Hz}$, where there is a peak of $125 \mathrm{~N} . \mathrm{s} / \mathrm{m}$ and then a decrease in impedance up to $48 \mathrm{~Hz}$. There is another wide peak of around $100 \mathrm{~N} . \mathrm{s} / \mathrm{m}$ in the range 70 to $130 \mathrm{~Hz}$ and the impedance increases in proportion to frequency with a mass-like behaviour.

\subsection{Transmissibility}

As expected, the transmissibility differed to different points on the hand (Figure 6). At the fingertips, where there is less mass and less soft tissue, resonances occurred at higher frequencies. This is consistent with the results of Scalise et al. [29] who found that transmissibility along the $z_{h}$ direction differed significantly between distal and proximal finger joints.

\section{FIGURE 6 ABOUT HERE}

The greatest mean transmissibility occurred for the fingertips in condition \#7 where it reached 2.85 around $22 \mathrm{~Hz}$ for point \#3, 2.7 at $20 \mathrm{~Hz}$ for point 6, and $2.1 \mathrm{at} 24 \mathrm{~Hz}$ for point \#9. In condition \#7, the fingers were outside the plate and their high magnitude vibration corresponds to rigid rotation around the metacarpal-phalangeal joints. This was confirmed by the response at the interphalangeal joints that vibrated at the same frequencies but with less amplitude.

The same rigid rotation of the portion of the finger outside the plate was found in condition \#6, but the movement was less and occurred at higher frequencies, around $30-40 \mathrm{~Hz}$.

Distal and proximal inter-phalangeal joints of the index, middle, ring, and little fingers also had damped resonances at higher frequencies between 100 and $200 \mathrm{~Hz}$ (seen in conditions \#1, \#2 and \#3), that reached a transmissibility of 1.5 at point 13 in condition \#1 and 1.6 at point 12 in condition \#2.

The metacarpal-phalangeal joints (i.e., the knuckles at points \#5, \#8, \#11 and \#16), had their greatest transmissibility in conditions \#1 and \#5 around $40 \mathrm{~Hz}$, with a transmissibility of about 1.9 for point \#16 and 1.6 for point \#5. In condition \#6 they had the same shape but the transmissibility was attenuated, and another small peak appeared around $70 \mathrm{~Hz}$ that is more evident in condition \#7. The knuckle of the little finger has a different behaviour, more similar to point \#13 than to the knuckles of the other fingers.

As may be expected, the behaviour over the rear of the hand from point \#15 to point \#24 was similar among conditions \#1, \#5, and \#6, with a resonance around $40 \mathrm{~Hz}$ with greatest transmissibility (about 1.6) at point \#15 and point \#16.

The thumb exhibited a peculiar behaviour. The response of point \#1 was flat in conditions $\# 1$ and \#5 at frequencies less than $110 \mathrm{~Hz}$, while in conditions \#6 and \#7 the response 
was similar to the other knuckles, with a valley around $50 \mathrm{~Hz}$ and a peak at $70 \mathrm{~Hz}$. However, point \#2 was similar to points \#15 and \#16. The transmissibility to both points decreases greatly in conditions \#3 and \#4, where the thumb was no more in contact with the plate.

Up the arm, it was mostly the lower frequencies, less than 50 to $60 \mathrm{~Hz}$, that were transmitted to the elbow and they were attenuated in proportion to increased distance from the driving point and reduced contact area at the driving point, from condition \#1 to condition \#4. In the posture adopted by the subjects in this experiment, the hand and arm can be roughly considered as a beam rotating around the elbow joint.

Although the results are not quantitatively comparable, because they were obtained in different conditions and the response functions are different, the findings seem consistent with energy transmission along the $x_{h}$-axis from proximal knuckles to the shoulder reported by Sörensson and Burström [20].

\subsection{Inter-subject variability}

The extent and form of inter-subject variability must be considered when interpreting averages from a group of subjects because individual differences in the resonance frequencies reduce the visibility of the resonances in the mean response. Averaging suppresses peaks that are not present in all subjects and causes resonances to appear more damped than they are in reality.

As an example, in the range 14 to $40 \mathrm{~Hz}$, where the first wide peak of the mean apparent mass occurred in conditions \#1 and \#7, some subjects had two resonance peaks, but after averaging there is only one wide peak (see Figure 7).

\section{FIGURE 7 ABOUT HERE}

The transmissibility of each of the 14 subjects to point \#6 in condition \#1 shows that the first peak in the mean transmissibility around $50 \mathrm{~Hz}$ is the result of averaging some high peaks over the range 40 to $70 \mathrm{~Hz}$ with local minima (Figure 8).

\section{FIGURE 8 ABOUT HERE}

A large variability in transmissibility was especially apparent on the distal and middle phalanges and was probably related to the anthropometric characteristics of the fingers (see Figure 9). 


\subsection{Operating Deflection Shapes}

The parallel measurement of apparent mass (or mechanical impedance) and transmissibility to many points along the finger-hand-arm system, together with the calculation of the deflection shapes makes possible to relate the biodynamic response at the driving point to the motions of the different parts of the finger-hand-arm system. The upper limbs are complex structures and it is reasonable to assume that at different frequencies the driving point response is influenced by relative motion between different parts of the system.

Frequencies of interest in the driving point response functions (Figure 4) and the transmissibilities (Figure 6), were selected and then interpreted in terms of the overall motion of the hand-arm system seen by animating the calculated deflection shapes. Because they were calculated from the mean moduli and phases of the transmissibilities, each movement shape represents the average over all subjects.

In this paper, the animation of motion is represented by 3D wire frame plots reflecting the motion at each of the 41 measurement locations. For each location, the distance from the reference position is proportional to the product between the magnitude and the phase at the selected frequency. In the figures, the phase is positive for points shown above the reference position and negative for points shown below the reference position. When either the magnitude or phase is close to zero, the point is shown coincident with the reference location, with the physical meaning that either the absolute movement at that location is small (magnitude close to zero), or that the motion is in phase with the motion at the point of excitation, like a rigid mass (phase close to zero) so that the relative motion between the location and the excitation is small.

\subsubsection{Condition \#1: whole hand and all fingers in contact with the vibrating plate}

Deflection shapes for condition \#1 at $16 \mathrm{~Hz}(\mathrm{~A}), 36 \mathrm{~Hz}(\mathrm{~B}), 56 \mathrm{~Hz}(\mathrm{C})$ and $110 \mathrm{~Hz}(\mathrm{D})$ are presented in Figure 10. These frequencies were chosen as they represent, respectively, the start and the end of the wide apparent mass resonance, the peak, and the following minimum of the mechanical impedance.

\section{FIGURE 10 ABOUT HERE}

At low frequencies all points move together and vibration propagates to all points on the arm with a phase shift that is proportional to the distance from the vibration source. The fingertips are shown in black because their phase is close to zero, and at low frequencies their transmissibility is close to 1.0. This means they move like rigid masses placed on the plate, without absorbing energy from the vibration of the plate. 
As the vibration increases in frequency, points on the arm reverse their phase at a frequency proportional to their distance from the elbow.

At higher frequencies, only points on the hand vibrate, with a phase shift proportional to the thickness of the different parts of the hand.

No deflection shape other than the obvious rotation of the whole hand-arm around the elbow was observed in this condition. The apparent mass remains high because the whole arm vibrates together, including the locations were the mass is concentrated.

\subsubsection{Condition \#2: whole fingers in contact with the vibrating plate}

In condition \#2 at $12 \mathrm{~Hz}$, points on the rear of the hand and on the arm (where most of the mass of the system is concentrated) move together (Figure 11). This may explain the peak in the driving point apparent mass at this frequency (Figure 4).

\section{FIGURE 11 ABOUT HERE}

With increasing frequency, different points start to move out-of-phase with each other, and around $46 \mathrm{~Hz}$ all points on the arm move in anti-phase to the movement of the hand. This suggests that the minimum in the driving point apparent mass can be explained not by supposing that less mass is involved in the vibration but by different masses in the system moving in anti-phase, so that their contribution to the apparent mass at the driving point is cancelled. The deflection shape is consistent with the structure of the arm, with rotation between the hand and the arm around the wrist.

At higher frequencies, the transmission of vibration up the arm is greatly reduced, and at $70 \mathrm{~Hz}$ and higher frequencies the arm is almost immobile, so that its negative contribution to the driving point apparent mass disappears and a small resonance peak, due mainly to vibration in the central part of the hand, becomes apparent. It is possible to see in Figure 6 that points in the centre of the rear of the hand have a transmissibility resonance peak around $70 \mathrm{~Hz}$.

\subsubsection{Condition \#3: distal and middle phalanges in contact with the vibrating plate}

The lowest resonance of the apparent mass in condition \#3 is at $12 \mathrm{~Hz}$, as in condition \#2. The deflection shape is similar, except because the thumb is no longer in contact with the plate its phase delay is greater. The first peaks of the apparent mass and mechanical impedance still correspond to rigid rotation around the elbow (see A and B in Figure 12).

\section{FIGURE 12 ABOUT HERE}

At higher frequencies, points on the arm start to reverse their phase, and the apparent mass at the driving point consequently decreases. At $46 \mathrm{~Hz}$, as in condition \#2, the arm is 
moving in anti-phase to the hand, but in this condition the thumb follows the arm and not the hand. At higher frequencies only the vibration of the fingers remains high.

\subsubsection{Condition \#4: distal phalanges in contact with the vibrating plate}

In condition \#4, there are no clear resonances visible in either the apparent mass or the mechanical impedance. At $12 \mathrm{~Hz}$ the deflection shape is similar to that in other conditions, except that neither the thumb nor the little finger are in contact with the plate, so their phase shift is high at low frequencies (see Figure 13).

Around 26 and $30 \mathrm{~Hz}$ there is a resonance of the little finger that rigidly rotates around its metacarpophalangeal joint. As in other conditions, as the frequency increases the arm starts to move in a different way with respect to the hand and, again, at $46 \mathrm{~Hz}$ the motion is completely out of phase. The thumb, as expected, moves with the arm, and the motion of the little finger, still rotating rigidly about its base, is also out of phase with the motion of the hand.

\section{FIGURE 13 ABOUT HERE}

At higher frequencies (greater than $200 \mathrm{~Hz}$ ) only the fingertips in contact with the plate continue to vibrate.

\subsubsection{Conditions \#5, \#6 and \#7: palm in contact with the vibrating plate with no contact at distal, middle and proximal phalanges, respectively}

In conditions \#5 to \#7, the motion was only measured at points 1 to 24 . The operating deflection shapes for conditions \#5 and \#6 are not reported here, as they were similar to those shown for condition \#1. Condition \#7 (palm in contact with the vibrating plate with no contact at the fingers) is more interesting, as all the deflection shapes were dominated by rigid rotation of the index, middle and ring fingers outside the plate around the knuckles (see Figure 14).

At $22 \mathrm{~Hz}$, in the middle of the peak in the apparent mass, the fingers move in phase with the rest of the hand and the little finger. At $46 \mathrm{~Hz}$, the fingers move in anti-phase with the hand and cause the corresponding minima in the apparent mass and mechanical impedance.

\section{FIGURE 14 ABOUT HERE}

The second peak in the apparent mass and mechanical impedance around 60 to $70 \mathrm{~Hz}$ correspond to a second peak in all transmissibilities to points in the centre of the hand measured in condition \#7. 


\section{Conclusions}

Measurements of the transmissibility to many different points on the hand-arm system, and the calculation of spectral operating deflection shapes showing the relative motion between the various parts of the hand-arm system, assist the interpretation of apparent mass and mechanical impedance measured at the driving point. The transmissibilities increase understanding of vibration responses to hand-transmitted vibration and are required for the development of representative biodynamic models. The transmissibilities for a hand pressing down on a flat plate show large relative motions at some frequencies and help to explain features in the apparent mass found here and also reported in some previous studies.

Compared to accelerometers, the scanning laser Doppler vibrometer allows quicker measurement of transmissibility to many points while eliminating problems due to misalignments of single-axis accelerometers and the effects of their mass on the loading of the skin. The spectral operating deflection shapes calculated in this study appear consistent with the structure of the hand-arm system but were carried out on the skin surface. Further research should explore the limitations of the method as well as applying it to improve understanding of responses to hand-transmitted vibration.

Some vibration responses of the hand-arm system, such as large relative motion at specific frequencies and in specific postures, may be hypothesized as the cause of specific injuries in the fingers, hand, or arm. Increased understanding of the vibration responses of the hand-arm system should encourage the focusing of attention on the relation between features of the vibration exposure (e.g. frequencies of vibration and limb posture) and specific disorders. Increased understanding of the vibration responses will also assist consideration of factors that can modify the vibration at specific locations and may be expected to influence injury and other consequences of hand-transmitted vibration.

\section{Acknowledgements}

The authors wish to express their gratitude to all those in the Mechanical and Thermal Measurement Research Group of the Università Politecnica delle Marche and in the Human Factors Research Unit of the Institute of Sound and Vibration Research at the University of Southampton who contributed to this work with their competence and availability. Special appreciation is due to Prof. Enrico P. Tomasini, Dr. Lorenzo Scalise and Prof. Nicola Paone. 


\section{References}

[1] International Organization for Standardization (2001) Mechanical vibrationMeasurement and evaluation of human exposure to hand-transmitted vibration. International Standard, ISO 5349.

[2] International Organization for Standardization (2005) Human response to vibration Measuring instrumentation. International Standard, ISO 8041.

[3] Lidström I. M. (1977) Vibration injury in rock drillers, chiselers, and grinders. Some views on the relationship between the quantity of energy absorbed and the risk of occurrence of vibration injury. Proceedings of the International Occupational Hand-Arm Vibration Conference. NIOSH, Cincinnati, US.

[4] Bovenzi M., Petronio L. and Di Marino F. (1980) Epidemiological survey of shipyard workers exposed to hand-arm vibration. International Archives of Occupational and Environmental Health, 46(3).

[5] Reynolds D. D. and Falkenberg R. J. (1984) A study of hand vibration on chipping and grinding operators. Part II: Four degree of freedom lumped parameter model of the vibration response of the human hand. Journal of Sound and Vibration, 95, 499-514.

[6] Reynolds D. D., Basel R., Wasserman D. E. and Taylor W (1984) A study of hand vibration on chipping and grinding operators. Part III: Power levels into the hands of operators of pneumatic tools used in chipping and grinding operators. Journal of Sound and Vibration, 95, 515-524.

[7] Griffin M.J. (1997) Measurement, evaluation, and assessment of occupational exposures to hand-transmitted vibration. Occupational and Environmental Medicine, 54, (2), 73-89.

[8] Griffin M.J. (2008) Measurement, evaluation, and assessment of peripheral neurological disorders caused by hand-transmitted vibration. International Archives of Occupational and Environmental Health, 81, (5), 559-573.

[9] Bovenzi M. (1998) Exposure-response relationship in the hand-arm vibration syndrome: an overview of current epidemiology research. Int Arch Occup Environ Health, $71,509-519$.

[10] Griffin M.J., Bovenzi,M., Nelson,C.M. (2003) Dose response patterns for vibrationinduced white finger. Journal of Occupational and Environmental Medicine, 60, 16-26.

[11] Burström L. (1990) Absorption of vibration energy in the human hand-arm. Doctoral thesis, Luleå University of Technology. 
[12] Burström L. (1997) The influence of biodynamic factors on the mechanical impedance of the hand and arm. Int Arch Occup Environ Health, 69, 437 - 446.

[13] Gurram R., Rakheja S. and Brammer A.J. (1995) Driving-point mechanical impedance of the human hand-arm system: synthesis and model development. Journal of Sound and Vibration, 180 (3), 437-458.

[14] Gurram R., Rakheja S. and Gouw G.J. (1995) Mechanical impedance of the human hand-arm system subject to sinusoidal and stochastic excitations. International Journal of Industrial Ergonomics, 16, 135-145.

[15] Dong R. G., Schopper A. W., McDowell T. W., Welcome D. E., Wu J. Z., Smutz W. P., Warren C. and Rakheja S. (2004) Vibration energy absorption (VEA) in human fingershand-arm system. Medical Engineering \& Physics, 26, 483-492.

[16] Dong R.G., Welcome D.E., McDowell T.W. and Wu J.Z. (2004) Biodynamic response of human fingers in a power grip subjected to a random vibration. Journal of Biomechanical Engineering, 126.

[17] Aldien Y., Marcotte P., Rakheja S. and Boileau P.E. (2005) Mechanical impedance and absorbed power of hand-arm under $\mathrm{x}_{\mathrm{h}}$-axis vibration and role of hand forces and posture. Industrial Health, 43, 495-508.

[18] International Organization for Standardization (1998) Mechanical vibration and shock - Free, mechanical impedance of the human hand-arm system at the driving point. International Standard, ISO 10068.

[19] Burström L. and Lundström R. (1994) Absorption of vibration in the human hand and arm. Ergonomics, 37, 879-890.

[20] Sörensson A. and Burström L. (1997) Transmission of vibration energy to different parts of the human hand-arm system. Int Arch Occup Environ Health, 70, 199-204.

[21] Burström L. and Lundström R. (1998) Portable equipment for field measurement of the hand's absorption of vibration energy. Safety Science, Vol. 2(1),15-20.

[22] Dong R.G., McDowell T.W. and Welcome D.E. (2005) Biodynamic response at the palm of the human hand subjected to a random vibration. Industrial Health, 43, 241-255.

[23] Dong R.G., Wu J.Z., McDowell T.W., Welcome D.E. and Schopper A.W. (2005) Distribution of mechanical impedance at the fingers and the palm of the human hand. Journal of Biomechanics, 38, 1165-1175. 
[24] Dong R.G., Wu J.Z., Welcome D.E. and McDowell T.W. (2005) Estimation of vibration power absorption density in human fingers. Journal of Biomechanical Engineering Copyright, 127, 849-856.

[25] Dong R.G., Dong J.H., Wu J.Z. and Rakheja S. (2007) Modeling of biodynamic responses distributed at the fingers and the palm of the human hand-arm system. Journal of Biomechanics. Journal of Biomechanics, 40, 2335-2340..

[26] Matsumoto Y. and Griffin M.J. (1998) Movement of the upper-body of seated subjects exposed to vertical whole-body vibration at the principal resonance frequency. Journal of Sound and Vibration, 215 (4), $743-762$.

[27] Kitazaki S. and Griffin M.J. (1998) Resonance behaviour of the seated human body and effects of posture. Journal of Biomechanics, 31, $143-149$.

[28] Valentino M., Rapisarda V., Scalise L., Paone N., Santarelli L., Fenga C. and Rossi G.L. (2004) A new method for the experimental assessment of finger haemodynamic effects induced by a hydraulic breaker in operative conditions. J Occup Health, 46, 113124.

[29] Scalise L., Rossetti F. and Paone N. (2007) Hand vibration: non-contact measurement of local transmissibility. Int Arch Occup Environ Health, DOI $10.1007 / \mathrm{s} 00420-007-0190-3$.

[30] Kitazaki S. and Griffin M. J. (1995) A data correction method for surface measurement of vibration on the human body. Journal of Biomechanics, 28 (7), 885-890.

[31] Pinotti M., Paone N., Santos F. A. and Tomasini E. P. (1998) Carotid artery pulse wave measured by a laser vibrometer. Proceedings of SPIE Vol. 3411 - Third International Conference on Vibration Measurements by Laser Techniques: Advances and Applications, Ancona, Italy.

[32] Rossi G. L. and Tomasini E. P. (1994) Proposal of a new measurement technique for hand-arm vibration analysis. Proceedings of SPIE Vol. 2358 - First International Conference on Vibration Measurements by Laser Techniques: Advances and Applications, Ancona, Italy.

[33] Rossi G.L. and Tomasini E.P. (1995) Hand-arm vibration measurement by a laser scanning vibrometer. Measurement, 16, 113 - 124.

[34] Deboli R., Miccoli G. and Rossi G.L. (1999) Human hand-transmitted vibration measurements on pedestrian controlled tractor operators by a laser scanning vibrometer. Ergonomics, 42 (6), $880-888$. 
[35] Tomasini E.P., Revel G.M: and Castellini P. (2001) Laser Based Measurement. Encyclopedia of Vibration, Pages 699-710. Academic Press, London.

[36] International Organization for Standardization (1997) Mechanical vibration and shockHuman exposure-Biodynamic coordinate systems. International Standard, ISO 8727.

[37] O'Boyle M.J. and Griffin M.J. (2006) Predicting the effect of the push force on the transmission of vibration through glove materials to the palm of the hand. In: Proceedings of the 10th International Conference on Hand-Arm Vibration, Flamingo Hilton Resort, Las Vegas, Nevada, USA, 1 - 11 June 2004. pp 417-427.

\section{LIST OF FIGURE CAPTIONS}

Figure 1 The seven conditions of contact with the vibrating plate.

Figure 2 Construction line and numbering of scanning points defined on the finger-handarm of subjects.

Figure 3 Experimental test bench layout, equipment and inter-connections.

Figure 4 Comparison of mean moduli of $(A)$ the driving point apparent mass and $(B)$ the driving point mechanical impedance for conditions \#1 to \#7 (as illustrated in Figure 1): cond.\#1; - - cond.\#2; cond.\#3; .......... cond.\#4;

- - - - cond.\#5; cond.\#6; cond.\#7.

Figure $5 \mathrm{~A}$ comparison between the condition \#1 driving point mechanical impedance and results reported by Gurram (1995) for vibration along the $x_{\mathrm{h}}$ direction: — present study; — Mishoe, $6.9 \mathrm{~m} / \mathrm{s}^{2}$; - - Mishoe, $34.3 \mathrm{~m} / \mathrm{s}^{2} ;$. . B Burström; — - Hesse; — - - . . Hempstock; - - - - Reynolds $19, \mathrm{~mm} ;{ }^{* * *}$ Reynolds, $38 \mathrm{~mm}$; • • Lundström; Gurram, sine; $\Delta \Delta$ Gurram, random.

Figure 6 Mean magnitude of the transmissibilities to all measurement points cond.\#1; cond.\#2; cond.\#3; ......... cond.\#4;

--- - cond.\#5; cond.\#6; cond.\#7.

Figure 7 Apparent mass off all 14 subjects and mean apparent mass measured in condition \#1 (A) and condition \#7 $\quad$ (B): $\longrightarrow$ mean transmissibility; transmissibilities of individual subjects.

Figure 8 Transmissibility of each of the 14 subjects and the mean transmissibility measured at point $\# 9$ in condition \#1 mean transmissibility; transmissibilities of individual subjects. 
Figure 9 Transmissibility of each of the 14 subjects and the mean transmissibility measured to point \#4 (A), point \#17 (B), point \#25 (C) and point \#30 (D) in condition \#1: mean transmissibility; transmissibilities of individual subjects.

Figure 10 Operating deflection shapes in condition \#1 (whole hand and all fingers in contact with the vibrating plate) at $16 \mathrm{~Hz}(\mathrm{~A}), 36 \mathrm{~Hz}(\mathrm{~B}), 56 \mathrm{~Hz}(\mathrm{C})$ and $110 \mathrm{~Hz}(\mathrm{D})$ : reference position;

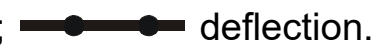

Figure 11 Operating deflection shapes in condition \#2 (whole fingers in contact with the vibrating plate) at $12 \mathrm{~Hz}(\mathrm{~A}), 30 \mathrm{~Hz}(\mathrm{~B}), 46 \mathrm{~Hz}(\mathrm{C})$ and $70 \mathrm{~Hz}(\mathrm{D})$ : reference position; deflection.

Figure 12 Operating deflection shapes in condition \#3 (distal and middle phalanges in contact with the vibrating plate) at $12 \mathrm{~Hz}(\mathrm{~A}), 22 \mathrm{~Hz}(\mathrm{~B}), 46 \mathrm{~Hz}(\mathrm{C})$ and $118 \mathrm{~Hz}(\mathrm{D})$ : reference position; deflection.

Figure 13 Operating deflection shapes in condition \#4 (distal phalanges in contact with the vibrating plate) at $12 \mathrm{~Hz}(\mathrm{~A}), 26 \mathrm{~Hz}(\mathrm{~B}), 46 \mathrm{~Hz}(\mathrm{C})$ and $200 \mathrm{~Hz}(\mathrm{D})$ : reference position; $\longrightarrow$ deflection.

Figure 14 Operating deflection shapes in condition \#7 (palm in contact with the vibrating plate with no contact at the fingers) at $22 \mathrm{~Hz}(\mathrm{~A})$ and $46 \mathrm{~Hz}(\mathrm{~B})$ : reference position; $\longrightarrow$ deflection. 
condition \#1

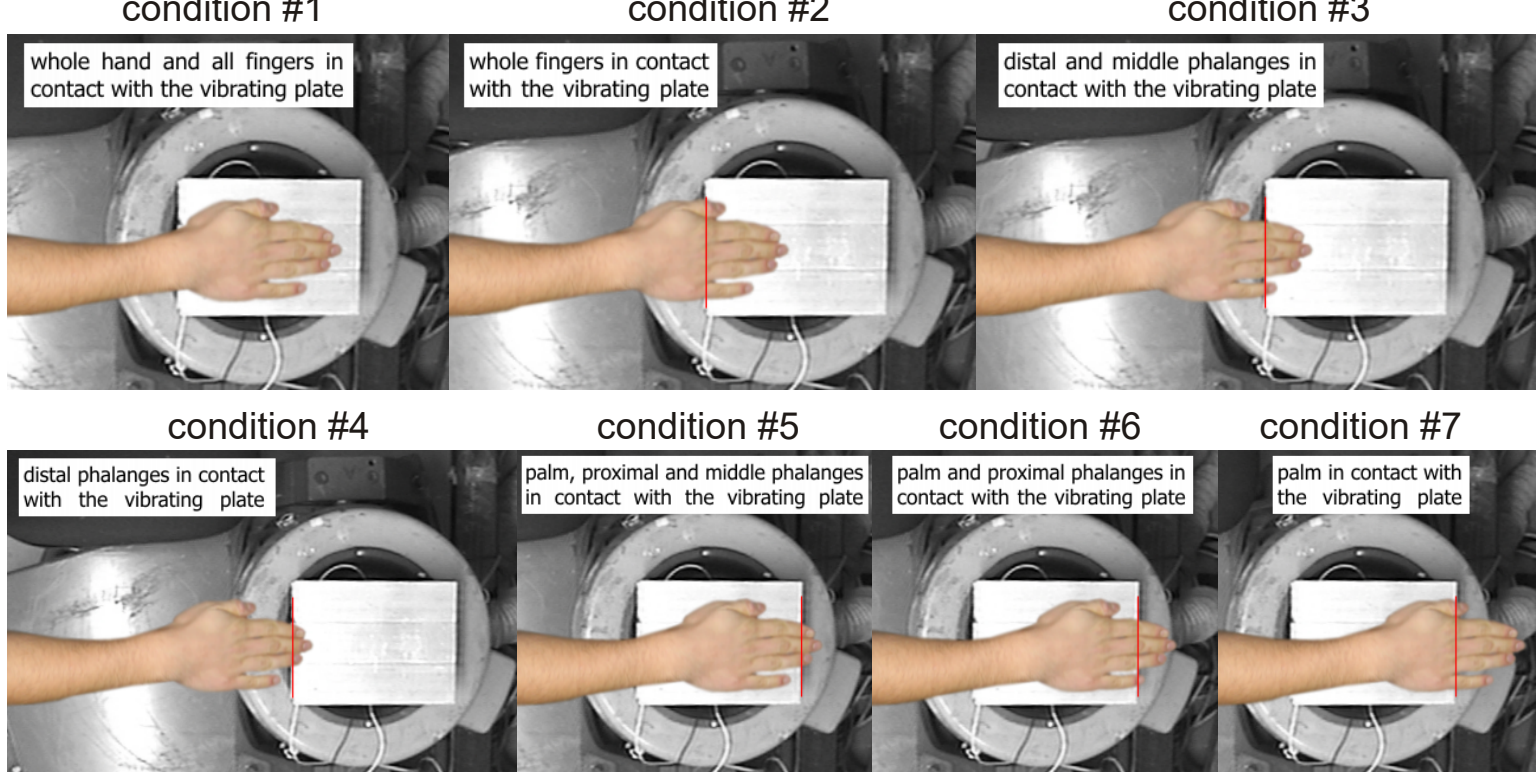

Figure 1 The seven conditions of contact with the vibrating plate. 


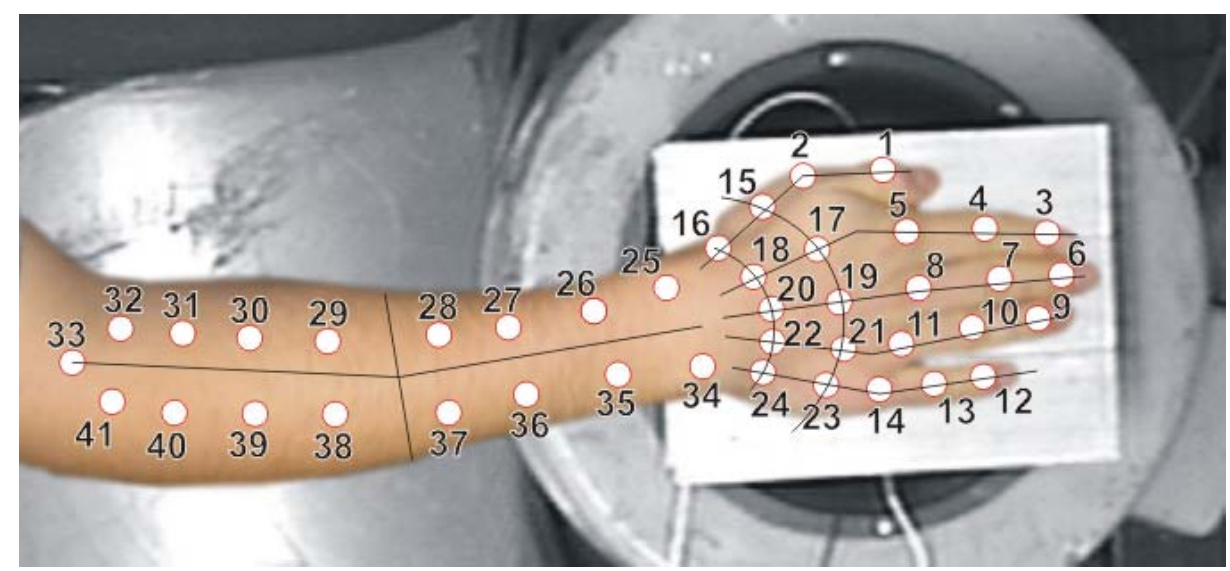

Figure 2 Construction line and numbering of scanning points defined on the finger-handarm of subjects. 


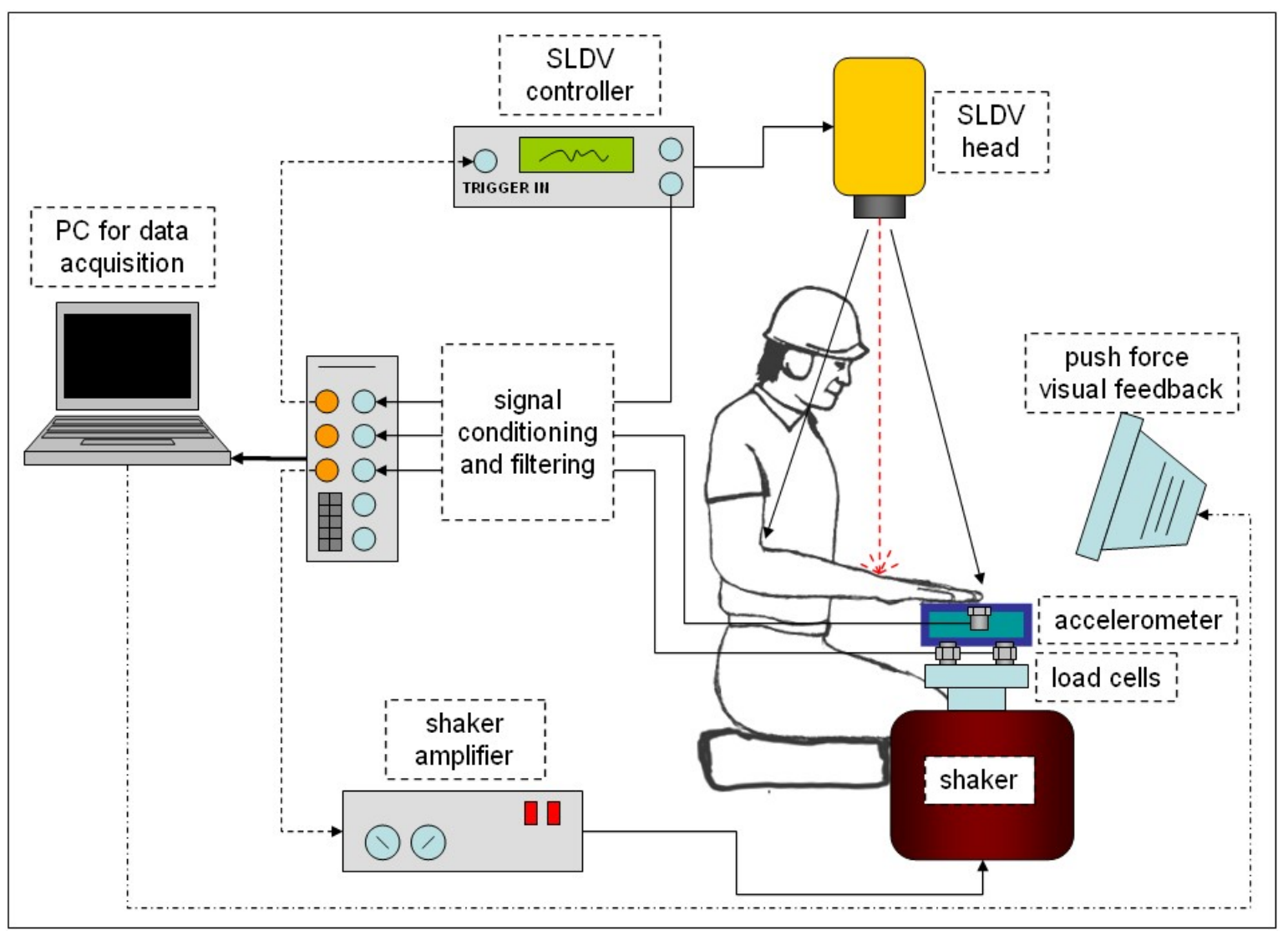

Figure 3 Experimental test bench layout, equipment and inter-connections. 

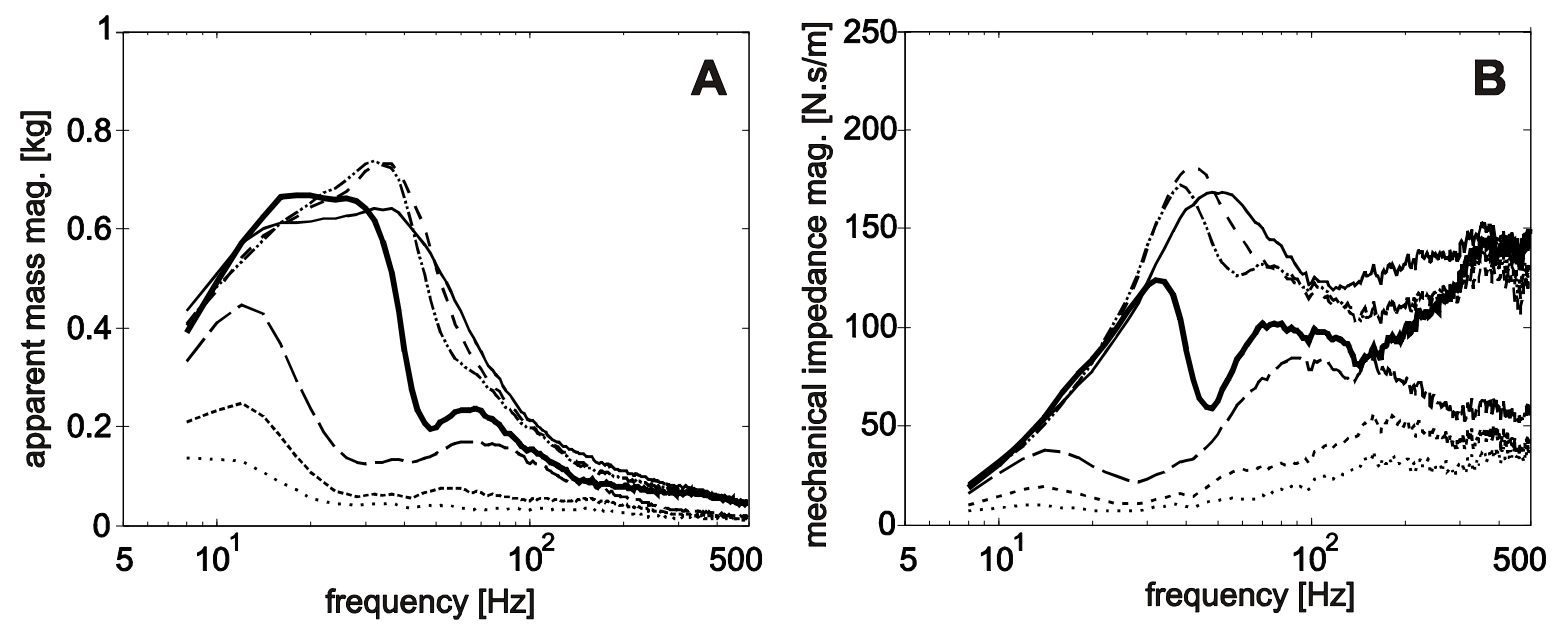

Figure 4 Comparison of mean moduli of $(A)$ the apparent mass and $(B)$ the mechanical impedance for conditions \#1 to \#7 (as illustrated in Figure 1): cond.\#1;

- - cond.\#2; cond.\#3; cond.\#4; cond.\#5; cond.\#6; 


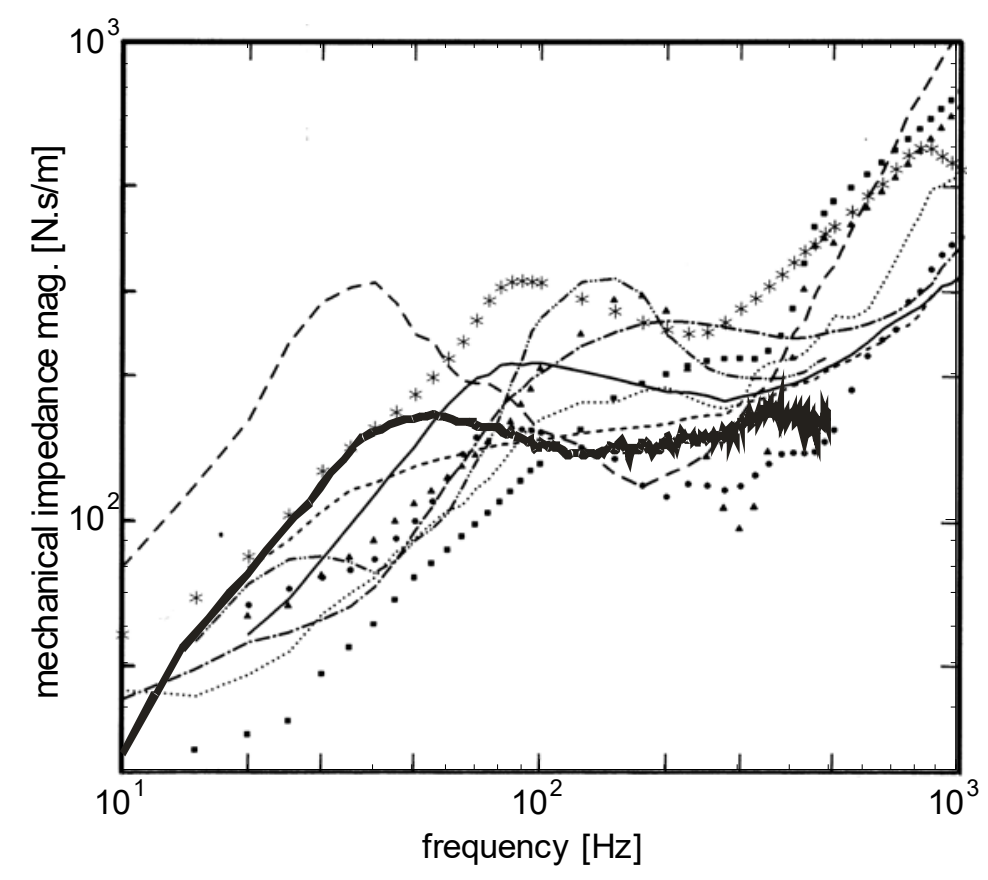

Figure $5 \mathrm{~A}$ comparison between the condition \#1 driving point mechanical impedance and results reported by Gurram (1995) for vibration along the $x_{\mathrm{h}}$ direction: — present study; — Mishoe, $6.9 \mathrm{~m} / \mathrm{s}^{2}$; - - Mishoe, $34.3 \mathrm{~m} / \mathrm{s}^{2} ;$. . . Burström; — - Hesse; — - _ . . Hempstock; - - - - Reynolds 19, mm; ${ }^{* *}$ Reynolds, 38 mm; • • Lundström; Gurram, sine; $\Delta \Delta$ Gurram, random. 


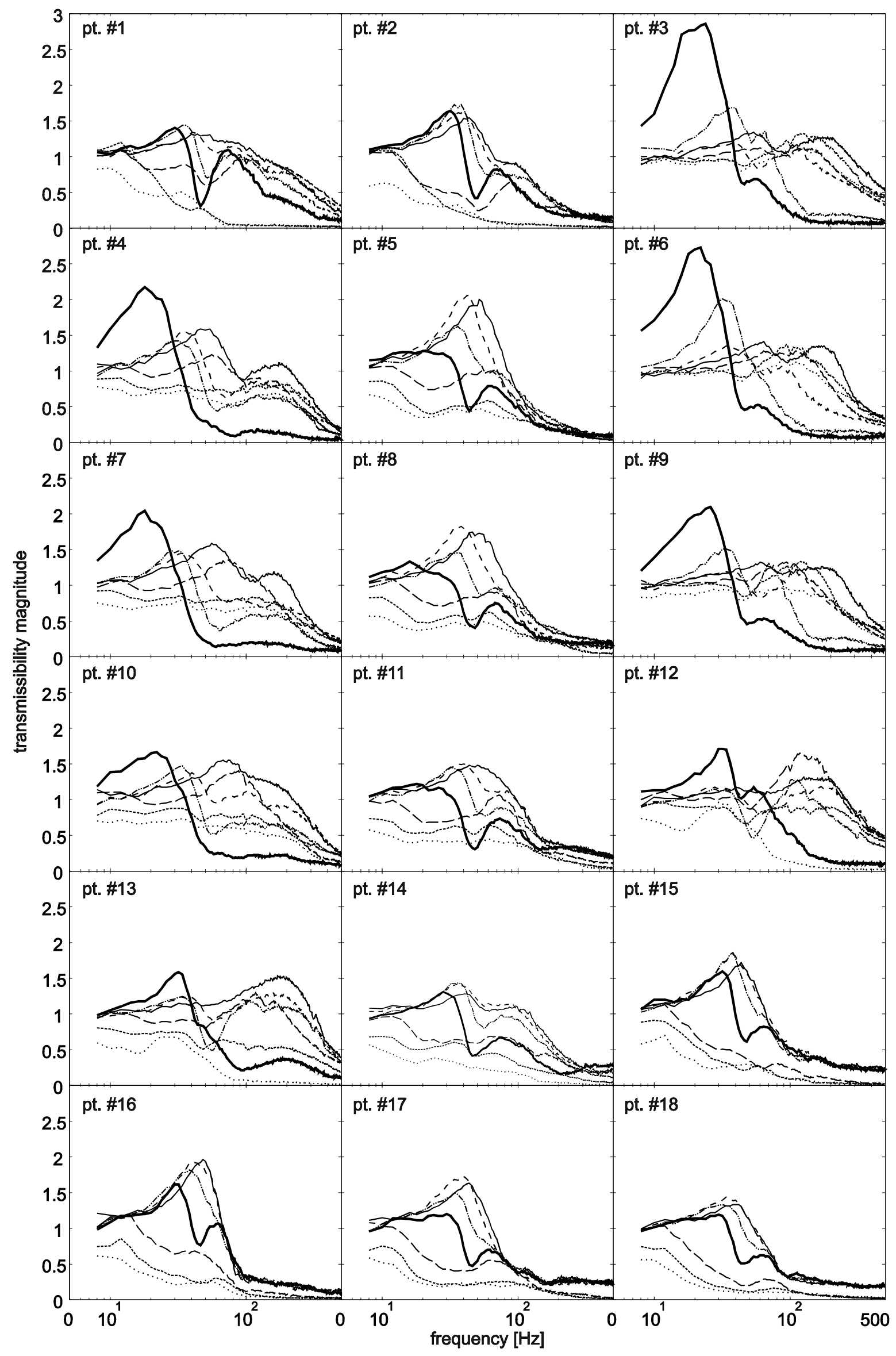




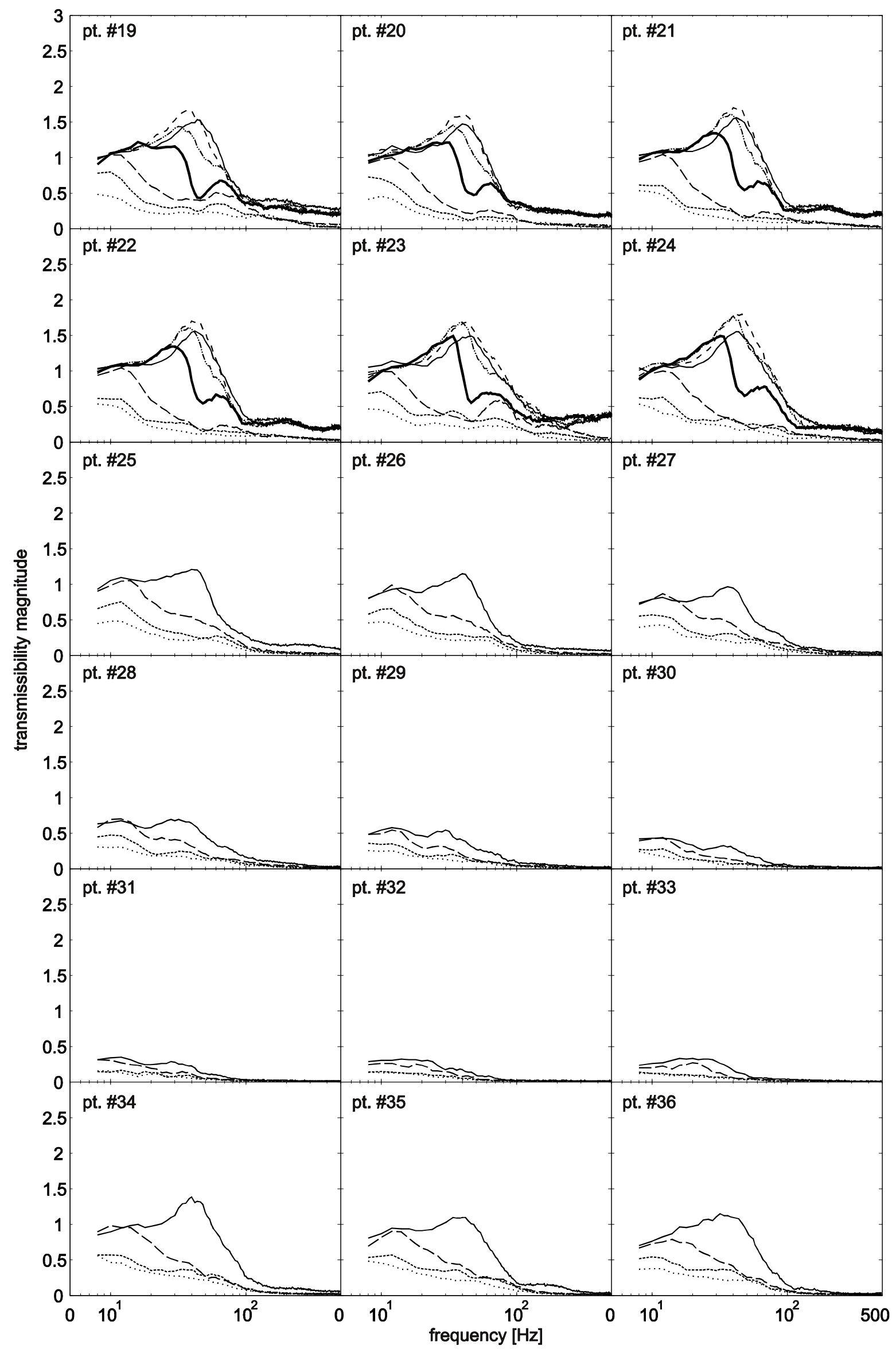




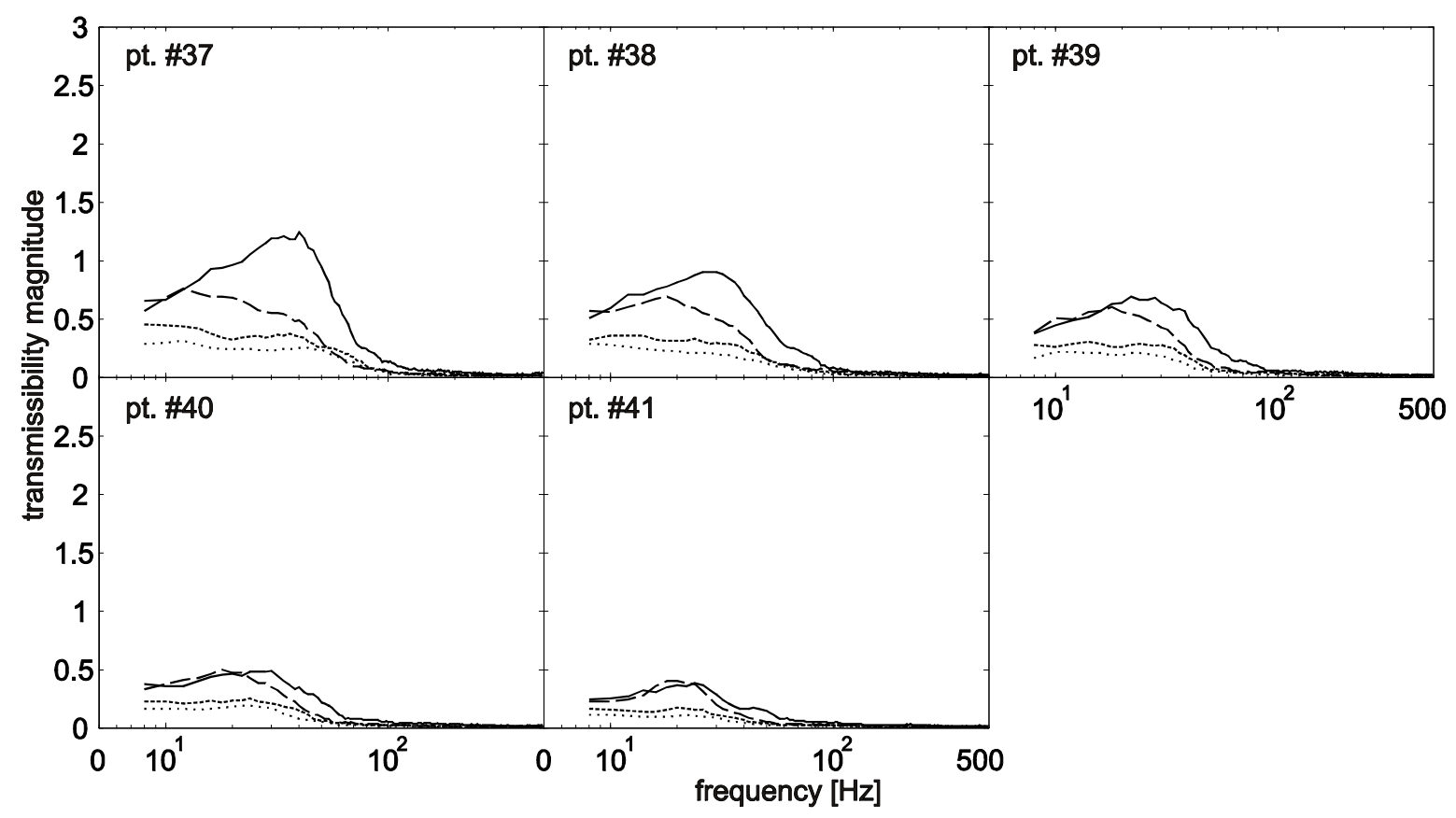

Figure 6 Mean magnitude of the transmissibilities to all measurement points cond.\#1; - - cond.\#2; cond.\#3; .......... cond.\#4; . cond.\#5; -...-.....- cond.\#6; cond.\#7. 


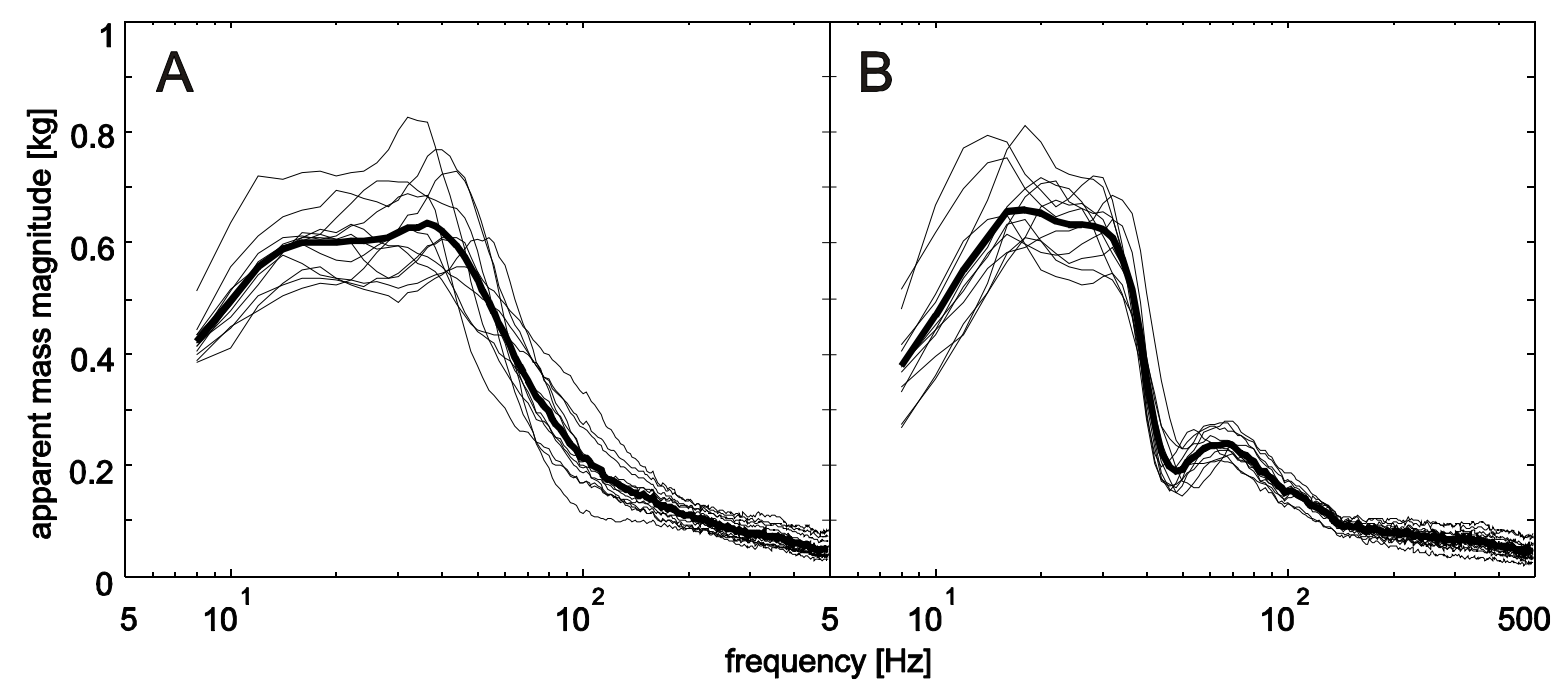

Figure 7 Apparent mass off all 14 subjects and mean apparent mass measured in condition \#1 (A) and condition \#7 (B): transmissibilities of individual subjects. 


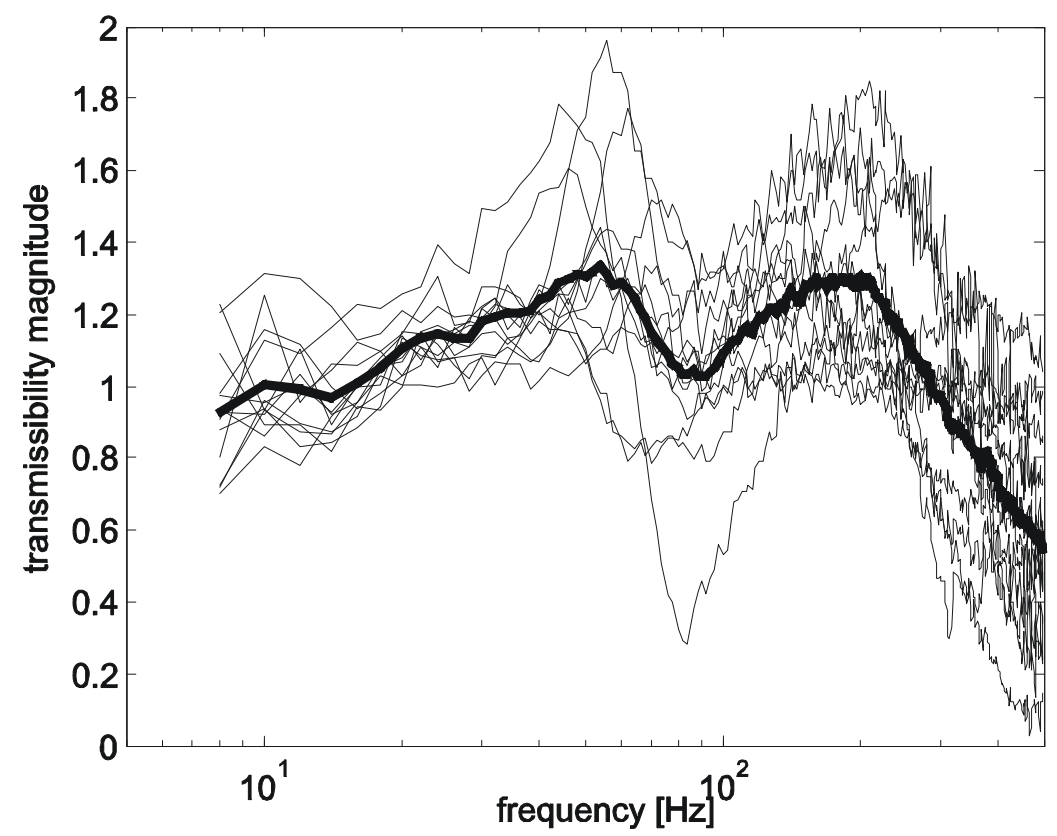

Figure 8 Transmissibility of each of the 14 subjects and the mean transmissibility measured at point \#9 in condition \#1 mean transmissibility; transmissibilities of individual subjects. 


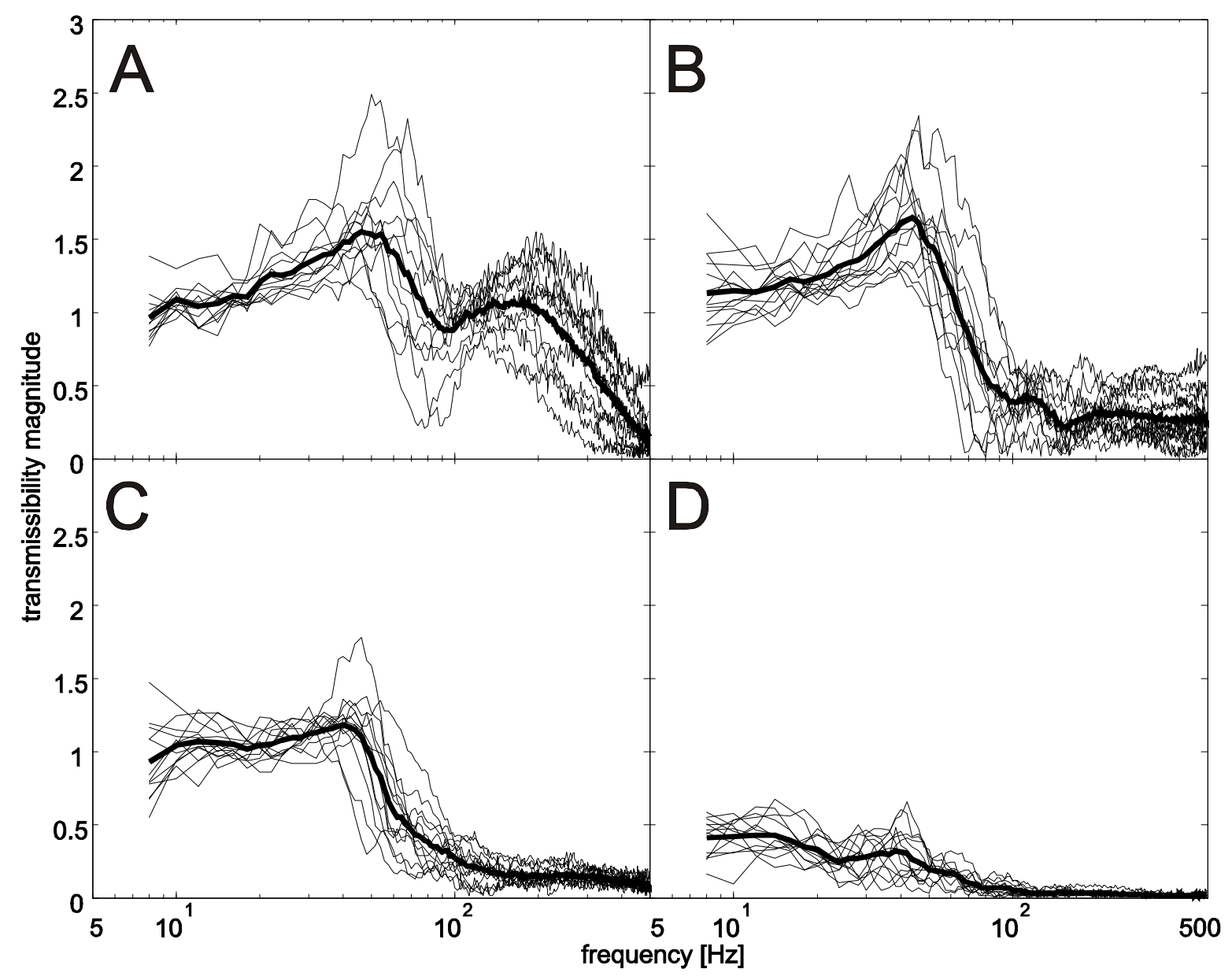

Figure 9 Transmissibility of each of the 14 subjects and the mean transmissibility measured to point \#4 (A), point \#17 (B), point \#25 (C) and point \#30 (D) in condition \#1.: mean transmissibility; transmissibilities of individual subjects. 


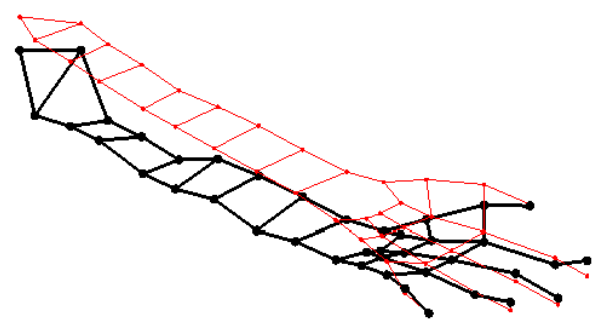

A

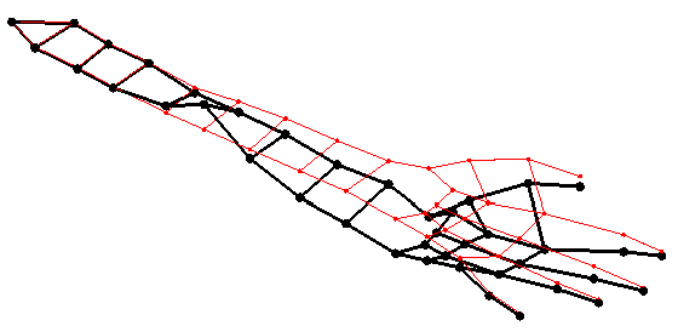

C

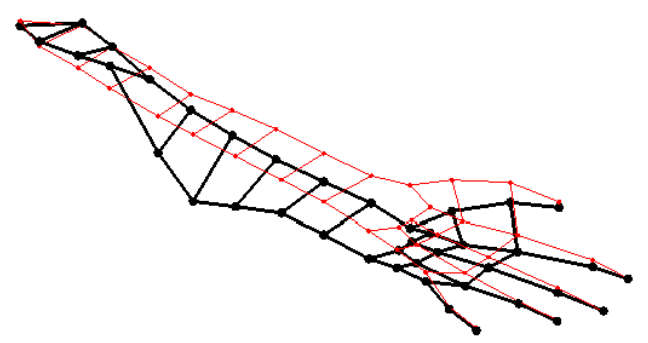

B

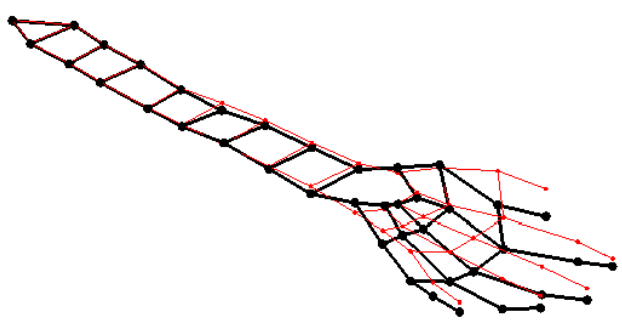

D

Figure 10 Operating deflection shapes in condition \#1 (whole hand and all fingers in contact with the vibrating plate) at $16 \mathrm{~Hz}(\mathrm{~A}), 36 \mathrm{~Hz}(\mathrm{~B}), 56 \mathrm{~Hz}(\mathrm{C})$ and $110 \mathrm{~Hz}(\mathrm{D})$ : reference position; deflection. 


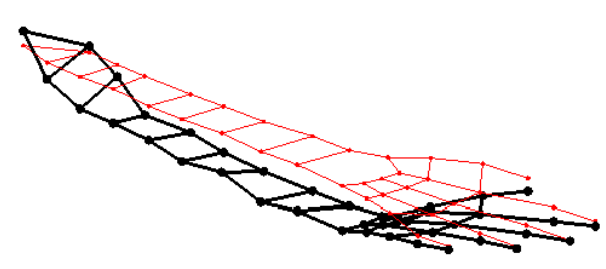

A

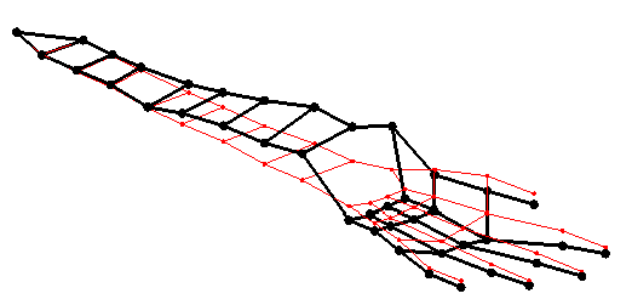

C

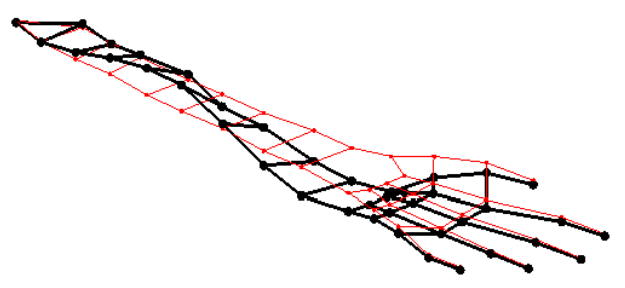

B

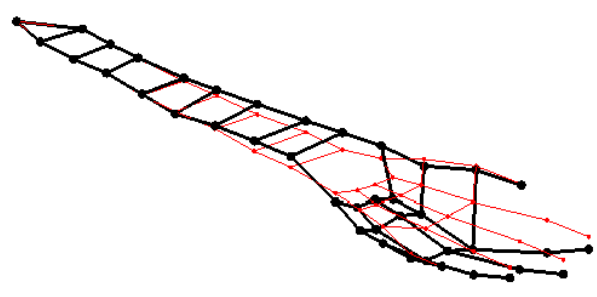

$\mathrm{D}$

Figure 11 Operating deflection shapes in condition \#2 (whole fingers in contact with the vibrating plate) at $12 \mathrm{~Hz}(\mathrm{~A}), 30 \mathrm{~Hz}(\mathrm{~B}), 46 \mathrm{~Hz}(\mathrm{C})$ and $70 \mathrm{~Hz}(\mathrm{D})$ : reference position; deflection. 


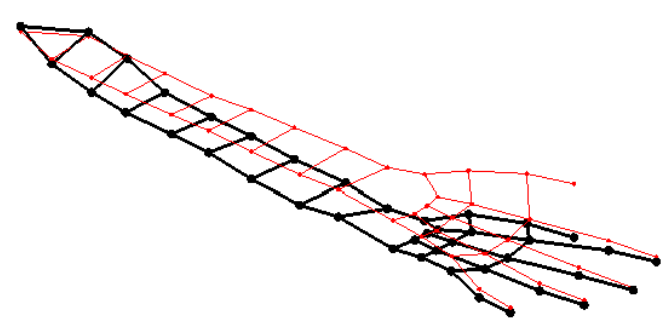

A

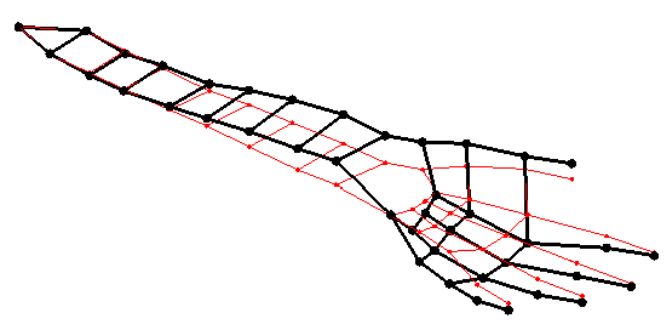

C

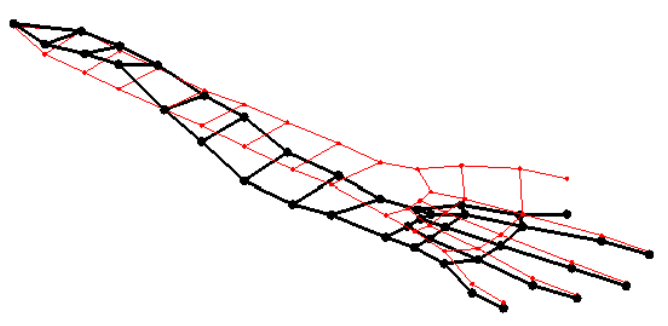

B

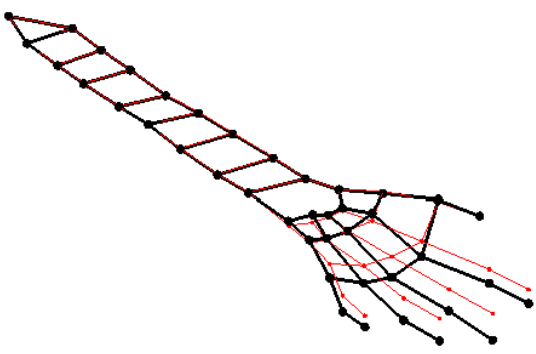

D

Figure 12 Operating deflection shapes in condition \#3 (distal and middle phalanges in contact with the vibrating plate) at $12 \mathrm{~Hz}(\mathrm{~A}), 22 \mathrm{~Hz}(\mathrm{~B}), 46 \mathrm{~Hz}(\mathrm{C})$ and $118 \mathrm{~Hz}(\mathrm{D})$ : reference position; deflection. 


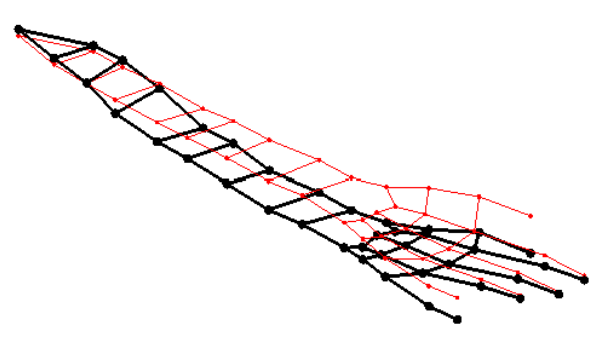

A

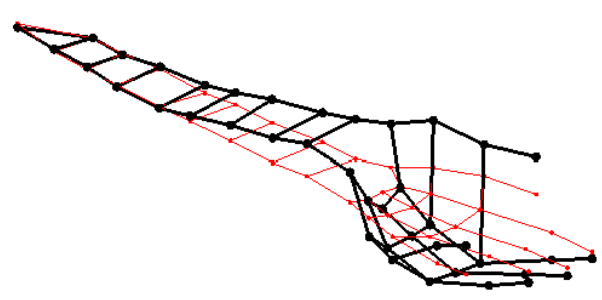

C

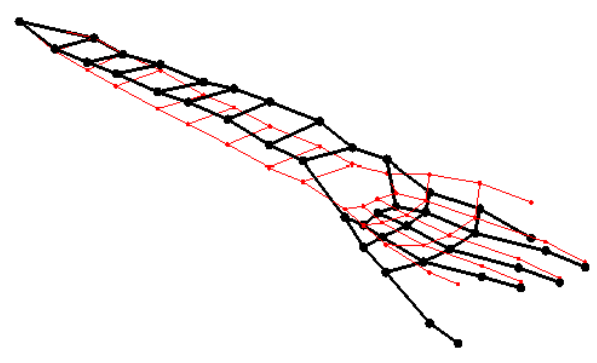

B

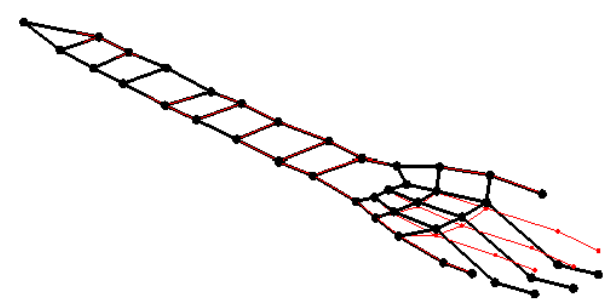

$\mathrm{D}$

Figure 13 Operating deflection shapes in condition \#4 (distal phalanges in contact with the vibrating plate) at $12 \mathrm{~Hz}(\mathrm{~A}), 26 \mathrm{~Hz}(\mathrm{~B}), 46 \mathrm{~Hz}(\mathrm{C})$ and $200 \mathrm{~Hz}(\mathrm{D})$ : reference position; deflection. 


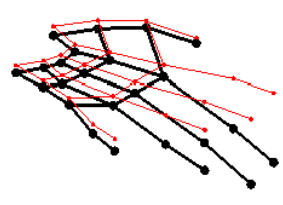

A

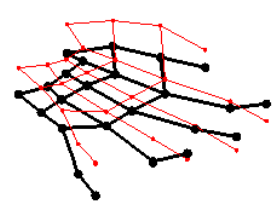

B

Figure 14 Operating deflection shapes in condition \#7 (palm in contact with the vibrating plate with no contact at the fingers) at $22 \mathrm{~Hz}(\mathrm{~A})$ and $46 \mathrm{~Hz}(\mathrm{~B})$ : reference position; $\longrightarrow$ deflection. 